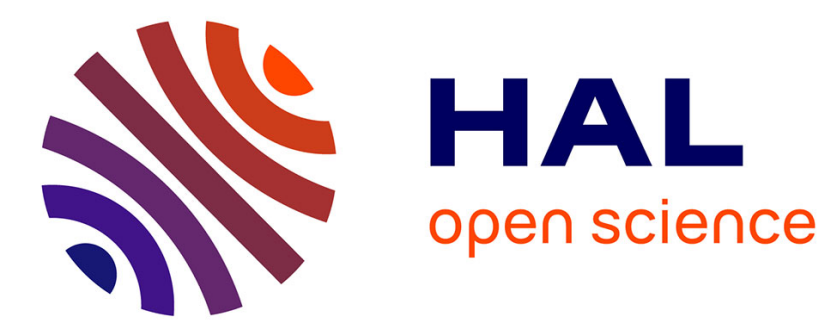

\title{
On optimization possibility for ocean acoustic tomography system
}

\author{
A. Semenov
}

\section{To cite this version:}

A. Semenov. On optimization possibility for ocean acoustic tomography system. Journal de Physique IV Proceedings, 1994, 04 (C5), pp.C7-1087-C7-1090. 10.1051/jp4:19945239 . jpa-00252926

\section{HAL Id: jpa-00252926 https://hal.science/jpa-00252926}

Submitted on 1 Jan 1994

HAL is a multi-disciplinary open access archive for the deposit and dissemination of scientific research documents, whether they are published or not. The documents may come from teaching and research institutions in France or abroad, or from public or private research centers.
L'archive ouverte pluridisciplinaire HAL, est destinée au dépôt et à la diffusion de documents scientifiques de niveau recherche, publiés ou non, émanant des établissements d'enseignement et de recherche français ou étrangers, des laboratoires publics ou privés. 


\title{
On optimization possibility for ocean acoustic tomography system
}

\author{
A.G. SEMENOV
}

N.N. Andreev Acoustics Institute, Russian Academy of Sciences, 4 Shvernik str, Moscow 117036, Russia

\begin{abstract}
This work shows results of sound signal amplitude fluctuation measurements in comparably narrow envelope frequency spectrum interval from 1.5 to $6.0 \mathrm{mHz}$ obtained on different stationary tomographic systems - $100 \mathrm{~km}, 100 \mathrm{~Hz}$ in Barentz sea and $320 \mathrm{~km}, 400 \mathrm{~Hz}$ in okhotsk sea. Use of this range, from our point of view, in any ocean region allows to decrease influence of two meeting ocean wave processes - surface wind waves from high frequency side and internal as well as long surface waves from low frequency side. This interval according to several previously fulfilled oceanographic researches could be considered as some kind of "transparency window" for different natural ocean processes responsible for sound fluctuations spectrum. Measurements presented demonstrate such possibility and allow to choose optimal envelope frequency analysis interval for tomographic systems installed in quite different regions.
\end{abstract}

\section{INTRODUCTION}

Long range stationary acoustic system of many tens or hundreds kilometers by length are considered to be unique instrument of World oceans exploration. By means of such systems distant measurements of water mass movements parameters on wide temporal and spatial scale is possible and this method is called now - ocean tomography. It is of special importance for arctic and subarctic World ocean regions, where sometimes use of other local measuring devices is very difficult. Natural ocean waves influence on sound signal parameters was observed by multiple authors in different regions. For instance, many reports reflected frequency spectrum of sound interacting with wind troubled ocean surface, internal waves, tides, ocean vortices and other well known large scale inhomogeneities [1]. Sound amplitude statistical distribution study for many practical situations where different wave processes are responsible for sound propagation is known to be very important for tomographyc systems exploitation. This work is based on results of sound signal amplitude fluctuation measurements in comparably narrow envelope frequency spectrum interval from 1,5 to $6,0 \mathrm{mHz}$. Use of this range, from our point of view, in any ocean region allows to 
decrease influence of two meeting ocean wave processes - internal and long surface waves from low frequency side and surface wind waves from high frequency side. This interval due to several previously fulfilled oceanographic researches [1] could be considered as some kind of "transparency window" for different natural ocean processes responsible for sound fluctuation spectrum. Measurements [3] demonstrate such possibility and allow to compare said influence for two critical situations arising in quite different conditions of deep and shallow ocean subarctic regions, where available information predicts also different saturation degree of sound amplitude fluctuations expected [2].

\section{EXPERIMENTAL CONDITIONS AND ANALYSIS}

First stationary system was installed in Ochotsk sea between Sachalin and Iturup islands. It's length was approximately $320 \mathrm{~km}$ and maximum depth of trace - up to $3200 \mathrm{~m}$. Emitter and two detector units were situated not far from the shore at ocean bottom on depth 100 and $125 \mathrm{~m}$ correspondingly. Measurements were fulfilled in winter season, in special ship controlled hydrophysical conditions, where sound velocity profile has minimum near ocean surface (subsurface channel). Very narrow band sound signal of $388 \mathrm{~Hz}$ frequency was transmitted by omnidirectional in horizontal plane emitter during several winter days in the end of December. For frequency and length of trace values chosen, physical situation according to flatte diagram could be related to the case of fully saturated sound fluctuations [2]. Second sequence of measurements was undertaken in summer season in the South-East part of Barentz sea on stationary sound traces of approximately 60,90 and $120 \mathrm{~km}$ length. Sea depth was from 60 to $240 \mathrm{~m}$. All detectors were installed on sea bottom and emitter was also standing stationary on sea bottom and was feeded from research ship board. For that region in summer typical is hydrological situation which is known as "subbottom channel". Frequency of several day narrow band sound emission was chosen to be as low as 104 $\mathrm{Hz}$ to compensate internal wave influence. According to Flatte range-frequency diagram [2] this physical situation could be related to the case of nonsaturated sound amplitude fluctuations.

In both experiments weather conditions sometimes changed drastically for instance, wind changed from 1 to 5 balls. Nevertheless, due to special way of envelope filtering proposed and mentioned above yet, the yeild of wind surface waves influence was also excluded from fluctuations energy spectrum. That is why wind influence could be found only due to additive noise level increase registered on detectors side in the spectral band of emitter. But this problem was overcome in experiment by emission sound level increase or proper choice of predetector filter band on receiving side. It was shown by preliminary estimate that to ignore weather conditions in last aspect sense it is necessary to ensure for carrier sound signal to noise ratio not less than $10 \mathrm{~dB}$.

Computer data analysis programm included: predetector filtering of signal received in frequency bands $2,5 \mathrm{~Hz}$ for first experiment and 0,5 $\mathrm{Hz}$ for second one. Wider band for former experiment is due to practically observed widening of sound signal spectrum after multiple interactions with troubled ocean surface, detection of signals, digital band filtering of signal envelope by almost rectangular filter in interval from 1,5 to $6,0 \mathrm{mHz}$, calculation of mean value, mean square 
deviation of envelope from said mean value, and their relation which characterizes variation coefficient. Integration time for mean was not less than 3000 sec and for standard deviation analysis - approximately $1000 \mathrm{sec}$. By use of variation coefficient data obtained statistical treatment was fulfilled and probability distribution functions for both cases were also obtained.

\subsection{Analysis results}

Results of computer statistical treatment of variation coefficient data is shown in Table 1 for deep and shallow water experiments. For the case of nonsaturated fluctuations on sound traces of different length in Barentz sea it was also possible to show variation coefficient statistical parameters increasing with trace length tendency. It could be seen from Table 2 .

\begin{tabular}{lcc}
\hline $\begin{array}{l}\text { Experiment fluctuation } \\
\text { saturation degree[1] }\end{array}$ & & sound amplitude variation coefficient, \\
\cline { 1 - 1 } $\begin{array}{l}\text { Deep water, fully } \\
\text { saturated fluctuations }\end{array}$ & 10,35 & mean square deviation \\
$\begin{array}{l}\text { Shallow water, non- } \\
\text { saturated fluctuations }\end{array}$ & 5,90 & 2,80 \\
\hline
\end{tabular}

Table 1: Sound amplitude variation coefficient statistical parameters.

\begin{tabular}{ccc}
\hline Sound trace length & Sound amplitude variation coefficient, $\%$ \\
\cline { 2 - 3 } $\mathrm{km}$ & mean & mean square deviation \\
\hline 60 & 4,80 & 1,20 \\
90 & 5,90 & 1,27 \\
120 & 6,50 & 1,32 \\
\hline
\end{tabular}

Table 2: Stationary trace sound amplitude variation coefficient statistical parameters length dependence (nonsaturated fluctuation).

Probability density distribution function fitting experimental data due to results of reference [1] is of Rayleigh type with parameters shown in Table 1 and 2. But experiments also show that with accuracy necessary for practical purposes for the case of fully saturated fluctuations more simple Gauss type of distribution could be used instead of Rayleigh type. This two experimental distributions for deep and shallow ocean subarctic regions were presented in paper [3]. On Fig. 1 is shown Flatte diagramm distance - frequency of saturation degree for sound amplitude fluctuations and points on diagramm corresponds to experiments described in this report - three for nonsaturated and one 
for fully saturated parts of diagramm.

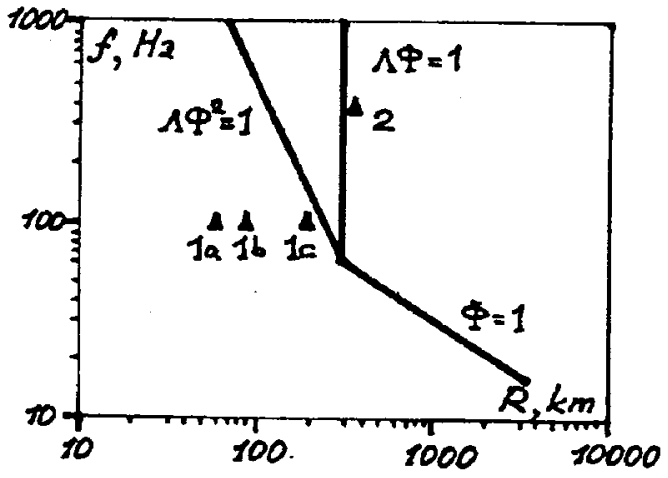

Fig.1.Distance-frequency Flatte diagramm [1] with parameters of experiments fulfilled in sub- arctic World ocean regions: 1a, 1b, 1c summer, South-East region of Barentz sea, 2 - winter, North-West region of Ochotsk sea.

\section{CONCLUSION}

Experimental statistical data for stationary sound trace amplitude fluctuations obtained for deep and shallow ocean subarctic regions in frequency band $1,5-6,0 \mathrm{mHz}$ of envelope spectrum correspond to known Flatte regimes of fully and nonsaturated fluctuations. Probability density distribution functions for variation coefficient of sound amplitude in this frequency range are shown to be of Rayleigh type. Parameters of distribution are found. For the case of nonsaturated fluctuations the increase of statistical parameters with increase of trace length is confirmed. Results obtained and tested in subarctic regions related to sound amplitude fluctuations envelope spectrum range choice could be used for tomographyc system construction optimization in quite different World ocean regions.

\section{REFERENCES}

[1] Flatte, s. et al. Sound transmission through a fluctuating ocean. (Cambrige University Press, 1979).

[2] Leblond P. and Mysak L., waves in the ocean. (Elsevier scientific Publishing Company, 1978)

[3] Khrekov A., Semenov A., Susarov V. Experimental comparison of sound amplitude fluctuations statistical characteristics in deep and shallow water subarctic regions. Procedings of European Conference on Underwater Acoustics, - Luxembourg, 14 to 17 September, 1992. ( Elsevier Scientific Publishing Company , 1992) pp.329-333 